\title{
NC-Clustering demonstrates heterospecificity of the cryptic ant species Temnothorax luteus (Forel, 1874) and T. racovitzai (BondRoIt, 1918) (Hymenoptera: Formicidae)
}

\author{
With 6 figures
}

BernhHard Seifert ${ }^{1}$, SAndor Csösz $^{2}$ and Andreas Schulz ${ }^{3}$

\begin{abstract}
${ }^{1}$ Senckenberg Museum of Natural History Görlitz, Am Museum 1, 02826 Görlitz, Germany. - bernhard.seifert@senckenberg.de ${ }^{2}$ Ecology Research Group, MTA-ELTE-MTM, Pázmány Péter sétány 1C, 1117 Budapest, Hungary. - sandorcsosz2@gmail.com

${ }^{3}$ Pletschbachstraße 13, 41540 Dormagen, Germany

Published on 2014-07-31
\end{abstract}

\section{Key words}

Cryptic species, exploratory data analysis, thermal niche

\section{Summary}

Evidence is presented that the W Mediterranean cryptic ant species Temnothorax luteus (ForeL, 1874) and T. racovitzai (Bondroit, 1918) are clearly separable by exploratory and hypothesis-driven data analyses of complex morphological data sets. Investigation was concentrated to the sympatric range of both species. 18 morphological characters were evaluated in a total of 178 workers originating from 64 nest samples. Classifications by hierarchical NC-Ward clustering, non-hierarchical NC-K-Means clustering, NC-NMDS-K-Means clustering and linear discriminant analysis coincided by $100 \%$ after reduction of the character set to the seven most discriminative characters. The type series of T. massiliensis (BondroIT, 1918) and T. racovitzai (BondroIT, 1918) were assigned to the same cluster with posterior probabilities of $\mathrm{p}=1.000$ in the former and $\mathrm{p}=0.9992$ in the latter. The type series of T. tristis (Bondroit, 1918) and T. luteus were allocated to another, clearly separated cluster with $\mathrm{p}=0.9999$ in each case. Accordingly, T. tristis is considered as junior synonym of T. luteus whereas T. massiliensis was established as junior synonym of T. racovitzai. The classification error of the LDA was $1.7 \%$ in 178 individuals. Despite a broad sympatric range, there are no suggestions to any nest samples containing a mixture of both phenotypes. This rejects the hypothesis that T. luteus and T. racovitzai could represent an intraspecific dimorphism. Significant interspecific differences of the two species in geographic distribution and thermal niche were demonstrated. Mean air temperature from May to August of 24 sampling sites of T. luteus was by $3.77^{\circ} \mathrm{C}$ cooler than in 21 sites of T. racovitzai $(\mathrm{p}<0.0001)$.

\section{Zusammenfassung}

Es wird gezeigt, dass die westmediterranen kryptischen Ameisenarten Temnothorax luteus (Forel, 1874) und T. racovitzai (Bondroit, 1918) mittels explorativer und hypothesengetriebener Analysen komplexer morphologischer Datensätze eindeutig unterscheidbar sind. Die Untersuchung konzentrierte sich auf das sympatrische Areal beider Arten. An 178 Arbeiterinnen aus 64 Nestproben wurden 18 morphologische Merkmale erfasst. Nach Reduktion auf die sieben meistseparierenden Merkmale ergab sich eine 100 \%ige Übereinstimmung der Klassifizierungen durch 
hierarchische NC-Ward-, nicht hierarchische NC-K-Means- und NC-NMDS-K-Means Clusteranalyse sowie durch eine lineare Diskriminanzanalyse. Die Typenserien von T. massiliensis (BondroIT, 1918) und T. racovitzai (BondROIT, 1918) wurden mit einer a posteriori Wahrscheinlichkeit von $\mathrm{p}=1.0000$ bzw. $\mathrm{p}=0.9992$ dem gleichen Cluster zugeordnet. Die Typenserien von T. tristis (Bondroit, 1918) und T. luteus wurden beide mit $\mathrm{p}=0.9999$ einem zweiten, deutlich vom ersteren separierten Cluster zugeordnet. Daraus ergibt sich, dass T. tristis ein jüngeres Synonym von T. luteus und T. massiliensis ein jüngeres Synonym von T. racovitzai ist. Der Klassifikationsfehler auf der Ebene der Individuen betrug $1.7 \%$ an 178 Arbeiterinnen. Trotz einer breiten Überlappung der Verbreitungsgebiete gibt es keine Hinweise auf phänotypisch gemischte Nester, was die Hypothese widerlegt, dass T. luteus and T. racovitzai einen intraspezifischen Polymorphismus repräsentieren könnten. Es wurden signifikante interspezifische Unterschiede in der geographischen Verbreitung und der thermischen Nischenkomponente gezeigt. Die mittlere Lufttemperatur von Mai bis August von 24 Fundorten von T. luteus war im Mittel um $3.77^{\circ} \mathrm{C}$ kälter als die von 21 Fundorten von T. racovitzai $(\mathrm{p}<0.0001)$.

\section{Introduction}

The identity of Temnothorax luteus (Forel, 1874) described from Grand Salève/ France and Ticino /Switzerland has remained obscure until very recently when Plateaux \& Cagniant (2012) discovered two type workers in the collection of Musée Zoologique Lausanne. These specimens carried no type labels but the argumentation of Plateaux \& Cagniant, based on the original morphological description and the localities reported by Forel, was conclusive. However, because their paper was based on very few investigated specimens and poor investigation standards, they published several diffuse and problematic decisions. In a synonymic list on page 430 and following Casevitz-Weulersse \& GalkowsKi (2009), Plateaux \& Cagniant published Temnothorax massiliensis (BondroIT, 1918) as a synonym of T. luteus and they considered T. racovitzai (BondRoIT, 1918) as a subspecies of T. luteus. However, results of exploratory and hypothesis-driven data analyses of complex character sets, show that T. massiliensis is no synonym of T. luteus and that T. racovitzai cannot be a subspecies of T. luteus. Furthermore, we want to assess the status of all five European taxa belonging to the T. luteus species complex and to demonstrate that there are two reliably delimited species, T. luteus and T. racovitzai, which differ significantly in morphology, distribution and in the thermal component of their climatic niches.

\section{Material and Methods \\ Material subject to numeric data recording}

For both sibling species, numeric data recording was performed in a total of 64 samples containing 178 workers and originating from 38 localities.

\section{Temnothorax luteus}

Numeric data recording was performed in a total of 106 workers from 38 different samples and 24 localities. These are in detail with collecting date given in the format yyyy. mm.dd and coordinates in international decimal format:
ANDORRA: Andorra City -9 km NNW, 1991.05.18, samples No $500 \mathrm{a}, 502\left[42.680^{\circ} \mathrm{N}, 1.470^{\circ} \mathrm{E}, 1750 \mathrm{~m}\right]$. FRANCE: Cucuron $-6 \mathrm{~km}$ NNE, Luberon Mts., 2009.03.15, samples No 574, 577, 584, 590, 593, 594 [43.816 ${ }^{\circ} \mathrm{N}, 5.458^{\circ} \mathrm{E}, 1009 \mathrm{~m}$ ]; Desaigres, 2008.04 (Darras) $\left[44.983^{\circ} \mathrm{N}, 4.517^{\circ} \mathrm{E}, 500 \mathrm{~m}\right]$; Grand Canyon du Verdon, $1992.05\left[43.770^{\circ} \mathrm{N}, 6.210^{\circ} \mathrm{E}, 500 \mathrm{~m}\right.$ ]; Grand Saleve, pre 1874 , type $T$. luteus $\left[46.130^{\circ} \mathrm{N}, 6.190^{\circ} \mathrm{E}, 900 \mathrm{~m}\right]$; La Tour de Carol, 2008.06.28, samples No d, h $\left[42.466^{\circ} \mathrm{N}, 1.890^{\circ} \mathrm{E}\right.$, $1500 \mathrm{~m}]$; Laruns, 2009.07.16 [42.917 $\mathrm{N}, \quad 0.450^{\circ} \mathrm{W}$, $800 \mathrm{~m}$ ]; Le Vigan -15 km NNW, 1994.07.09 [44.023 ${ }^{\circ} \mathrm{N}$, $\left.3.579^{\circ} \mathrm{E}, 900 \mathrm{~m}\right]$; Mas de Tence, 2007.07 [45.100 ${ }^{\circ} \mathrm{N}$, $4.333^{\circ} \mathrm{E}, 1000 \mathrm{~m}$; ; Mt. Ventoux, $1917.08 .12\left[44.133^{\circ} \mathrm{N}\right.$, $5.282^{\circ} \mathrm{E}, 1000 \mathrm{~m}$ ]; Nimes, $2008.07 .19\left[43.783^{\circ} \mathrm{N}, 4.283^{\circ} \mathrm{E}\right.$, $50 \mathrm{~m}]$; Nyons, 1981.04 .02 , No $9714\left[44.360^{\circ} \mathrm{N}, 5.150^{\circ} \mathrm{E}\right.$, $400 \mathrm{~m}$ ]: Puy de Dome: Sayat, pre 1918, type T. tristis $\left[45.830^{\circ} \mathrm{N}, 3.050^{\circ} \mathrm{E}, 500 \mathrm{~m}\right]$; Puy de Dome: Sayat, 2006.06.29 [45.830 ${ }^{\circ} \mathrm{N}, 3.050^{\circ} \mathrm{E}, 500 \mathrm{~m}$ ]; Puy de Dome: Sayat, $2006.07 .25\left[45.830^{\circ} \mathrm{N}, 3.050^{\circ} \mathrm{E}, 500 \mathrm{~m}\right.$ ]; Rochepaule, $2008.07\left[45.067^{\circ} \mathrm{N}, 4.450^{\circ} \mathrm{E}, 800 \mathrm{~m}\right.$ ]; S Col d'Izoard, Arvieux, 1994.07.29, No 396 [44.770, 6.730 E, $1750 \mathrm{~m}]$; St. Andre les Alpes, 1995.05, samples No 727, 729 [43.974 ${ }^{\circ} \mathrm{N}$, $6.505^{\circ} \mathrm{E}, 1000 \mathrm{~m}$ ]; Tournus $-5 \mathrm{~km} \mathrm{~W}, 1994.07 .08$, samples No $1,4,5$ and 007 [ $46.581^{\circ} \mathrm{N}, 4.834^{\circ} \mathrm{E}, 335 \mathrm{~m}$ ]; Volvic, 2006.06.29 [ $45.871^{\circ} \mathrm{N}, 3.029^{\circ} \mathrm{E}, 573 \mathrm{~m}$ ]. SPAIN: Chodos $-1 \mathrm{~km} \mathrm{W,} \mathrm{1991.05.18,} \mathrm{sample} \mathrm{No} 388\left[40.250^{\circ} \mathrm{N}, 0.300^{\circ} \mathrm{W}\right.$, $1250 \mathrm{~m}$ ]. SWITZERLAND: Brig, pre 1991, sample No 514 (A. Schulz) $\left[46.320^{\circ} \mathrm{N}, 7.973^{\circ} \mathrm{E}, 900 \mathrm{~m}\right]$; Locarno, below Mte. Bre, 1997.04.29, sample No 24.2 [46.181 ${ }^{\circ} \mathrm{N}$, $8.778^{\circ} \mathrm{E}, 880 \mathrm{~m}$ ]; Locarno, below Mte. Bre, 1997.05.27, sample No $24.3\left[46.181^{\circ} \mathrm{N}, 8.778^{\circ} \mathrm{E}, 880 \mathrm{~m}\right.$ ]; Locarno, below Mte. Bre, 2011.08.21, sample No 1, [46.181 ${ }^{\circ} \mathrm{N}$, $8.778^{\circ} \mathrm{E}, 880 \mathrm{~m}$ ]; Locarno: Ai Sassi, 1997.06.24, sample No 25.2 [ $46.200^{\circ} \mathrm{N}, 8.800^{\circ} \mathrm{E}, 580 \mathrm{~m}$ ]; Pfynwald, 1990.06 (A. Schulz) $\left[46.294^{\circ} \mathrm{N}, 7.560^{\circ} \mathrm{E}, 590 \mathrm{~m}\right]$.

\section{Temnothorax racovitzai}

Numeric data recording was performed in a total of 72 workers from 26 different samples and 21 localities. These are in detail: 
FRANCE: Aix-en-Provence, $1994.06\left[43.517^{\circ} \mathrm{N}, 5.467^{\circ} \mathrm{E}\right.$, $200 \mathrm{~m}$ ]; Aix-en-Provence $-10 \mathrm{~km} \mathrm{~N}, 2009.03 .13$, sample No $535\left[43.529^{\circ} \mathrm{N}, 5.586^{\circ} \mathrm{E}, 783 \mathrm{~m}\right]$; Apt $-10 \mathrm{~km} \mathrm{~S}$, Luberon Mts., 2009.03.14, sample No $565\left[43.787^{\circ} \mathrm{N}\right.$, $\left.5.352^{\circ} \mathrm{E}, 384 \mathrm{~m}\right]$; Banyuls, pre 1918 , type T. racovitzai $\left[42.480^{\circ} \mathrm{N}, 3.130^{\circ} \mathrm{E}, 10 \mathrm{~m}\right]$; Banyuls, 2009.06 .13 $\left[42.450^{\circ} \mathrm{N}, 3.083^{\circ} \mathrm{E}, 140 \mathrm{~m}\right]$; Banyuls $-4 \mathrm{~km} \mathrm{SE}, 1995.05$. 31 , sample No $799\left[42.466^{\circ} \mathrm{N}, 3.155^{\circ} \mathrm{E}, 100 \mathrm{~m}\right]$; Cerbere 2006.05.15 $\left[42.433^{\circ} \mathrm{N}, \quad 3.150^{\circ} \mathrm{E}, \quad 156 \mathrm{~m}\right] ;$ Cerbere $2007.09\left[42.433^{\circ} \mathrm{N}, 3.150^{\circ} \mathrm{E}, 156 \mathrm{~m}\right]$; Col de Banyuls, $2009.08\left[42.450^{\circ} \mathrm{N}, 3.050^{\circ} \mathrm{E}, 350 \mathrm{~m}\right]$; Col de Ceris, $2007.06 .23\left[42.468^{\circ} \mathrm{N}, 3.144^{\circ} \mathrm{E}, 140 \mathrm{~m}\right.$ ]; Cucuron $-6 \mathrm{~km}$ NNE, Luberon Mts., 2009.03.15, samples No 596, 597 [43.816 ${ }^{\circ} \mathrm{N}, 5.458^{\circ} \mathrm{E}, 1009 \mathrm{~m}$ ]; Dieulefit, pre 1900 (Forel) $\left[44.500^{\circ} \mathrm{N}, 5.113^{\circ} \mathrm{E}, 500 \mathrm{~m}\right.$ ]; Marseille, pre 1918 (Grouvelle), type T.massiliensis $\left[43.290^{\circ} \mathrm{N}, 5.390^{\circ} \mathrm{E}, 40 \mathrm{~m}\right.$ ]; Mt. Ventoux, 2010.08.22 [44.133 ${ }^{\circ} \mathrm{N}, 5.283^{\circ} \mathrm{E}, 1000 \mathrm{~m}$ ]; Nyons, 1981.04 .02 , sample No $9712\left[44.360^{\circ} \mathrm{N}, 5.150^{\circ} \mathrm{E}\right.$, $400 \mathrm{~m}]$. SPAIN: Chodos $-1 \mathrm{~km}$ W, 1991.05.18, sample No $380\left[40.253^{\circ} \mathrm{N}, 0.299^{\circ} \mathrm{W}, 1250 \mathrm{~m}\right.$ ]; Colldejou, 2009.10.20, samples No $-599,600,601\left[41.108^{\circ} \mathrm{N}, 0.864^{\circ} \mathrm{E}, 874 \mathrm{~m}\right.$ ]; Montsant Mts., 2007.04.03, samples No 16, 18 [41.279 ${ }^{\circ} \mathrm{N}$, $0.875^{\circ} \mathrm{E}, 980 \mathrm{~m}$ ]; Pauls vic., 2009.10.21, samples No 627, $628\left[40.925^{\circ} \mathrm{N}, 0.368^{\circ} \mathrm{E}, 983 \mathrm{~m}\right]$; Torroja del Priorat, 2007.04.03, sample No $15\left[41.215^{\circ} \mathrm{N}, 0.810^{\circ} \mathrm{E}, 330 \mathrm{~m}\right]$; Viella Baixa, 2009.10.23 [41.224 ${ }^{\circ} \mathrm{N}, 0.754^{\circ} \mathrm{E}, 265 \mathrm{~m}$ ].

\section{The type material and its labeling}

\section{Leptothorax tuberum r. luteus Forel, 1874}

Two workers labeled “ $ఛ$ ”, "Grd Salève, chez A. Varanen”, "Lectotype (bottom worker) Temnothorax luteus (Forel, 1874), des. Seifert 2011" [this labeling is consistent with the published lectotype designation of Plateaux \& Cagniant (2012) who did not physically label types]; lectotype with $\mathrm{CW}=588 \mu \mathrm{m}$; in Forel collection of $\mathrm{MZ}$ Lausanne.

\section{Leptothorax tristis BoNDROIT, 1918}

One type worker labelled "Sayat Puy de Dome $650 \mathrm{~m}$ M.Avel, "Leptothorax tristis Type Bondr."; IRSNB Bruxelles. Another worker in IRSNB Bruxelles, labelled "Mt.

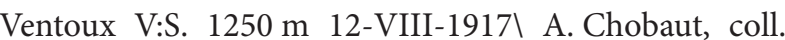
Minozzi" and "Leptothorax tristis Bondr.", cannot be considered a type because the locality Mt. Ventoux was not mentioned by BondroIT (1918).

\section{Leptothorax racovitzai BoNDRoIT, 1918}

Five workers labeled "Banyuls", "Leptothorax racovitzai Type Bondr., "Lectotypus des: Schulz 1994” [A. Schulz did not specify the lectotype specimen, the top specimen with $\mathrm{CW}=0.585 \mathrm{~mm}$ is published herewith as lectotype]; IRSNB Bruxelles.

\section{Leptothorax massiliensis BondRoIt, 1918}

Four syntype workers labeled "Marseille Grouvelle", "Leptothorax massiliensis Type Bondr."; IRSNB Bruxelles.

\section{Investigation Methods}

18 morphometric characters currently being used in taxonomy of Palaearctic Temnothorax (SEIFERT 2006, Csösz et al. 2013) were investigated. In bilaterally recorded characters, arithmetic means of both body sides were calculated. All measurements were made on mounted and dried specimens using a pin-holding stage, permitting full rotations around $\mathrm{X}, \mathrm{Y}$, and $\mathrm{Z}$ axes. A Leica M165C high-performance stereomicroscope equipped with a 2.0 planapochromatic objective (resolution 1050 lines $/ \mathrm{mm}$ ) was used at magnifications of $120-384 x$. The mean relative measuring error over all magnifications was $0.3 \%$. A Schott KL 1500 cold-light source equipped with two flexible, focally mounted light-cables, providing $30^{\circ}$-inclined light from variable directions, allowed sufficient illumination over the full magnification range and a clear visualization of silhouette lines. A Schott KL 2500 LCD cold-light source in combination with a Leica coaxial polarized-light illuminator provided optimal resolution of tiny structures and microsculpture at highest magnifications. Simultaneous or alternative use of the cold-light sources depending upon the required illumination regime was quickly provided by regulating voltage up and down. A Leica cross-scaled ocular micrometer with 120 graduation marks ranging over $52 \%$ of the visual field was used. To avoid the parallax error, its measuring line was constantly kept vertical within the visual field. Measurements of body parts always refer to real cuticular surface and not to the diffuse pubescence surface.

The process of species discrimination included four major routines:

(a) Reduction of errors in primary data recording as described in SEIFERT (2002).

(b) Removal of allometric variance (RAV) performed with the procedure described by SEIFERT (2008).

(c) Application of the exploratory data analyses Nest Centroid Clustering (NC-Clustering). This included a hierarchical method (NC-Ward), a non-hierarchical method (NC-K-Means) and a highly flexible ordination method (NC-NMDS-K-Means). These methods were described in more detail by SEIFERT et al. (2013) who also provided a script written in $\mathrm{R}$ and freely available under the GNU / GPL license from the following website: http//sourceforge.net/ projects/agnesclustering/.

(d) Checking of the demonstrated species clusters by linear discriminant analysis (LDA) also provided by SPSS 16.0 . 


\section{The morphometric characters}

CL - maximum cephalic length in median line; the head must be carefully tilted to the position with the true maximum. Excavations of occiput and/or clypeus reduce $\mathrm{CL}$.

CS - cephalic size; the arithmetic mean of CL and CW, used as a less variable indicator of body size.

CW - maximum cephalic width; the maximum is found in Temnothorax and Leptothorax usually across and including the eyes, exceptionally posterior of the eyes.

EYE - eye-size index: the arithmetic mean of the large (EL) and small diameter (EW) of the elliptic compound eye is divided by CS, i.e. $\mathrm{EYE}=(\mathrm{EL}+\mathrm{EW}) /(\mathrm{CL}+\mathrm{CW})$. All structurally visible ommatidia are considered.

FRS - distance of the frontal carinae immediately caudal of the posterior intersection points between frontal carinae and the lamellae dorsal of the torulus. If these dorsal lamellae do not laterally surpass the frontal carinae, the deepest point of scape corner pits may be taken as reference line. These pits take up the inner corner of scape base when the scape is fully switched caudad and produce a dark triangular shadow in the lateral frontal lobes immediately posterior of the dorsal lamellae of scape joint capsule.

MGr - depth of metanotal groove or depression, measured from the tangent connecting the dorsalmost points of promesonotum and propodeum; here given as per cent ratio of CS.

MH - in workers: with mesosoma in lateral view and measured orthogonal to "longitudinal mesosomal axis", $\mathrm{MH}$ is the longest measurable section line of mesosoma at mesopleural level (not height above all). "Longitudinal mesosomal axis" in lateral view is defined as straight line from the centre of propodeal lobe to the border point between anterior pronotal shield and propleuron. In gynes it is the longest section line directed perpendicular to the straight dorsal profile line of mesosoma (formed by mesonotum and scutellum). The lower reference point is usually the lowest part of mesopleuron.

MW - maximum mesosoma width; in gynes measured anteriorly of the tegulae.

ML - in workers: mesosoma length from caudalmost point of propodeal lobe to transition point between anterior pronotal slope and anterior propodeal shield (preferentially measured in lateral view; if the transition point is not well defined, use dorsal view and take the centre of the dark-shaded borderline between pronotal slope and pronotal shield as anterior reference point). In gynes: length from caudalmost point of propodeal lobe to the most distant point of steep anterior pronotal face.

PEH - maximum petiole height. The straight section of ventral petiolar profile at node level is the reference line perpendicular to which the maximum height of petiole node is measured.
PEL - diagonal petiolar length in lateral view; measured from anterior corner of subpetiolar process to dorsocaudal corner of caudal cylinder.

PEW - maximum width of petiole.

PoOc - postocular distance. Use a cross-scaled ocular micrometer and adjust the head to the measuring position of CL. Caudal measuring point: median occipital margin; frontal measuring point: median head at the level of the posterior eye margin. Note that many heads are asymmetric and average the left and right postocular distance.

PP - maximum width of postpetiole.

SL - maximum straight line scape length excluding the articular condyle as arithmetic mean of both scapes.

SP - maximum length of propodeal spines; measured in dorsofrontal view along the long axis of the spine, from spine tip to a line, orthogonal to the long axis, that touches the bottom of the interspinal meniscus (Fig. 4 in SEIFERT 2006). This mode of measuring is less ambiguous than other methods but it results in some spine length in species with reduced spines.

SPBA - the smallest distance of the lateral margins of the spines at their base. This should be measured in dorsofrontal view, since the wider parts of the ventral propodeum do not interfere with the measurement in this position. If the lateral margins of spines diverge continuously from the tip to the base, a smallest distance at base is not defined. In this case, SPBA is measured at the level of the bottom of the interspinal meniscus.

SPST - distance between the centre of propodeal stigma and spine tip. The stigma centre refers to the midpoint defined by the outer cuticular ring but not to the centre of real stigma opening that may be positioned eccentrically.

SPTI - the distance of spine tips in dorsal view; if spine tips are rounded or thick, the centres of spine tips are taken as reference points.

\section{Removal of allometric variance (RAV)}

In ant groups without extreme allometries removal of allometric variance (RAV) does not change the results of linear discriminant functions (SEIFERT 2008) but it may improve the success of exploratory data analyses. Exposing which deviations in shape characters or counts are no consequence of interspecific body size differences, RAV improves the explanatory power of comparative tables (Tab. 1). RAV was performed in workers as a mean of the parameters of 16 West Palaearctic Temnothorax species presented by 1443 evaluated specimens in the data files of the senior author. With CS given in mm, RAV was calculated for the assumption of all individuals having the same head size of $\mathrm{CS}=0.62 \mathrm{~mm}$ :

$\mathrm{CL} / \mathrm{CW}_{0.62}=\mathrm{CL} / \mathrm{CW} /\left(-0.0631^{\star} \mathrm{CS}+1.1366\right) * 1.0975$

$\mathrm{SL} / \mathrm{CS}_{0.62}=\mathrm{SL} / \mathrm{CS} /\left(-0.1193^{*} \mathrm{CS}+0.8298\right) * 0.7559$ 
$\mathrm{PoOc} / \mathrm{CL}_{0.62}=\mathrm{PoOc} / \mathrm{CL} /\left(-0.0259^{*} \mathrm{CS}+0.4044\right) * 0.3883$

$\mathrm{EYE} / \mathrm{CS}_{0.62}=\mathrm{EYE} / \mathrm{CS} /\left(+0.0395^{\star} \mathrm{CS}+0.1980\right) * 0.2225$

$\mathrm{FRS} / \mathrm{CS}_{0.62}=\mathrm{FRS} / \mathrm{CS} /\left(+0.0142^{\star} \mathrm{CS}+0.3417\right) * 0.3505$

$\mathrm{MW} / \mathrm{CS}_{0.62}=\mathrm{MW} / \mathrm{CS} /\left(+0.1424^{\star} \mathrm{CS}+0.5163\right) \star 0.6046$

$\mathrm{MH} / \mathrm{CS}_{0.62}=\mathrm{MH} / \mathrm{CS} /\left(-0.0060^{\star} \mathrm{CS}+0.5224\right) * 0.5186$

$\mathrm{ML} / \mathrm{CS}_{0.62}=\mathrm{ML} / \mathrm{CS} /\left(+0.1501^{\star} \mathrm{CS}+1.1208\right) * 1.2139$

$\mathrm{SPBA} / \mathrm{CS}_{0.62}=\mathrm{SPBA} / \mathrm{CS} /\left(+0.1563^{\star} \mathrm{CS}+0.1712\right) * 0.2681$

$\mathrm{SPTI} / \mathrm{CS}_{0.62}=\mathrm{SPWI} / \mathrm{CS} /\left(+0.1866^{\star} \mathrm{CS}+0.2047\right) * 0.3204$

$\mathrm{PEW} / \mathrm{CS}_{0.62}=\mathrm{PEW} / \mathrm{CS} /\left(+0.1129^{\star} \mathrm{CS}+0.1929\right) * 0.2629$

$\mathrm{PPW} / \mathrm{CS}_{0.62}=\mathrm{PPW} / \mathrm{CS} /\left(+0.0793^{\star} \mathrm{CS}+0.3120\right) * 0.3611$

$\mathrm{SP} / \mathrm{CS}_{0.62}=\mathrm{SP} / \mathrm{CS} /\left(+0.1543^{\star} \mathrm{CS}+0.1033\right) * 0.1989$

$\mathrm{SPST} / \mathrm{CS}_{0.62}=\mathrm{SPST} / \mathrm{CS} /\left(+0.1286^{*} \mathrm{CS}+0.1944\right) * 0.2741$

$\mathrm{PEH} / \mathrm{CS}_{0.62}=\mathrm{PEH} / \mathrm{CS} /\left(+0.0380^{\star} \mathrm{CS}+0.3384\right) * 0.3620$

$\mathrm{PEL} / \mathrm{CS}_{0.62}=\mathrm{PEL} / \mathrm{CS} /\left(+0.2043^{\star} \mathrm{CS}+0.3642\right) * 0.4909$

\section{Calculation of the thermal niche component}

As a rough measure of thermal niche, we estimated standard air temperature TAS in 2 meters above ground. Following the logic of SEIFERT \& PANNIER (2007: p. 162), TAS was calculated for a sampling site as mean air temperature of the period 1 May to 31 August of the nearest three meteorological stations. As the samples originate from the long period 1874 to 2012 we selected a reference before the recent acceleration of global warming and used the mean of the years 1961-1990 provided by Klimaabteilung der Zentralanstalt für Meteorologie und Geodynamik (1996). We corrected the data for an altitudinal temperature decrease of $0.661^{\circ} \mathrm{C}$ per $100 \mathrm{~m}$ according to the equation of SEIFERT and PANNIER (2007): TAS $=-0.694 \mathrm{LAT}+0.078 \mathrm{LON}-0.00661 \mathrm{ALT}+52.20$ where TAS is the predicted standard air temperature in ${ }^{\circ} \mathrm{C}$, LAT and LON are the geographical latitude and longitude in international decimal format, and ALT is the altitude above sea level in meters.

\section{Results and discussion}

\section{Diagnosis of the Temnothorax luteus complex}

Members of the Temnothorax luteus species complex (Figs 3-6) can be separated from other species by the character combination described below. Numeric data are given as overall means \pm standard deviation of individual workers without RAV-correction.

Whole ants light yellowish to yellowish brown, lacking any blackish or blackish brown pigmentation with exception of eyes; some body parts or the entire body may be infuscated. Dorsum of head capsule rather weakly longitudinally rugulose; small to very large areas of central vertex often completely smooth and shining. Relatively small-sized and long-headed in terms of the genus (CS $608 \pm 45 \mu \mathrm{m}, \mathrm{CL} / \mathrm{CW} 1.133 \pm 0.020)$. Scape longer than in most congeners (SL/CS $0.819 \pm 0.018$ ). Dorsal profile of mesosoma convex, without a metanotal groove. Propodeal spines rather long and acute (SP/CS $0.234 \pm$ 0.020 , SPST/CS $0.319 \pm 0.020$ ), significantly diverging in dorsal view (SPBA/CS $0.265 \pm 0.019$, SPTI/CS $0.346 \pm$ $0.026)$ and in lateral view moderately erected, deviating by $40-45^{\circ}$ from longitudinal mesosomal axis. Petiole in lateral view moderately pedunculate and of comparably low height (PEH/CS $0.351 \pm 0.014)$.

\section{Clustering, classification and synonymies}

NC-Ward, NC-K-Means and NC-NMDS-K-Means clustering considering 18 characters (i.e., the absolute size measure CS and 17 RAV-corrected shape characters) resulted in the demonstration of two main clusters (Fig. 1). These clusters are interpreted to represent two species Temnothorax luteus (ForeL, 1874) and Temnothorax racovitzai (BONDROIT, 1918). All three exploratory data analyses made a coincident assignment of the types series to either cluster: The type series of T. massiliensis (BONDROIT, 1918) shared a cluster with the type series of T. racovitzai and the type of T. tristis (BondroIT, 1918) clustered with the T. luteus type series. As a consequence, we consider T. massiliensis as a junior synonym of T. racovitzai and T. tristis a junior synonym of T. luteus. NC-K-Means and NC-NMDS-K-Means provided identical classifications for each of the 64 samples but they differed from NC-Ward in the allocation of three samples to the T. luteus cluster. These samples, placed by NC-Ward in the T. racovitzai branch, are marked in Fig. 1 with arrows. Running these three samples as wildcards in a linear discriminant analysis (LDA) confirmed their allocation to T. luteus. This $3: 1$ "majority decision" suggests that NC-Ward probably made three clustering errors when using the unselected set of all 18 characters. The LDA provided the following posterior probabilities for the type series: All four type specimens of T. massiliensis were assigned with $\mathrm{p}=1.000$ to the T. racovitzai cluster, the three type specimens of T. racovitzai were allocated with $\mathrm{p}=0.9997,0.9998$ and 0.9994 to the same cluster, the single type specimen of T. tristis was allocated with $\mathrm{p}=0.9998$ to the T. luteus cluster and the two type specimens of T. luteus with $\mathrm{p}=0.9999$ and 0.9999 to the same cluster. The classification error of the LDA was $2.2 \%$ in 178 worker individuals and $4.5 \%$ in a leave-oneout cross-validation LDA.

Accepting the hypotheses provided by NC-K-Means, NC-NMDS-K-means and the LDA using the 18-character system and running a stepwise LDA, reduced the number of characters to seven: $\mathrm{SL} / \mathrm{CS}_{0.62}, \mathrm{FRS} / \mathrm{CS}_{0.62}$, $\mathrm{EYE} / \mathrm{CS}_{0.62}, \mathrm{PEW} / \mathrm{CS}_{0.62}, \mathrm{SPST} / \mathrm{CS}_{0.62}, \mathrm{PEL} / \mathrm{CS}_{0.62}, \mathrm{ML} /$ $\mathrm{CS}_{0.62}$. As a result, the classifications of all three exploratory data analyses and the LDA were $100 \%$ congruent and the NC-Ward dendrogram became undisturbed (Fig. 2). With the number of individuals in the smallest class being 10.2 fold larger than the number of characters, an optimum condition for running an LDA was given. The type specimens of T. massiliensis were assigned with $\mathrm{p}=0.9999,1.000,1.000$, and 1.000 to the T. racovitzai cluster, the type specimens of T. racovitzai with 
$\mathrm{p}=0.9994,0.9996$ and 0.9982 to the same cluster, the type specimen of T. tristis was allocated with $\mathrm{p}=0.9999$ to the T. luteus cluster and the two type specimens of T. luteus with $\mathrm{p}=0.9999$ and 0.9999 to the same cluster. The classification error of the LDA was $1.7 \%$ in 178 individuals and $3.4 \%$ in a leave-one-out cross-validation LDA. These data give another clear indication for the presence of two well-separable species and the synonymies stated above. It might be asked if the different character syndromes of T. luteus and T. racovitzai could be the expression of a discrete intraspecific dimorphism rather than indicating different species. Discrete character syndromes feigning different species may be generated by the pleiotropic action of a single dominant - recessive gene encoding a transcription factor. Alternatively, but perhaps less likely, a non-recombinant cluster of linked genes may cause similar effects. Assuming conspecifity and panmictic behavior and considering that $83 \%$ of all samples were collected in the sympatric zone (precisely 27 samples of T. luteus and 26 of T. racovitzai), one should expect a significant number of nest samples containing both morphs. Considering within-sample variance of the posterior probabilities of the 7-character LDA, we found no sample in the whole material indicating a morph mixture on the $p>0.90$ level. This is a strong argument against intraspecific dimorphism.

Having only very few specimens available and based on a subjective guess, Plateaux \& Cagniant (2012) considered T. racovitzai as subspecies of T. luteus and published the new combination T. luteus racovitzai (BONDROIT). This idea is untenable because of the broadly overlapping geographical ranges of both taxa (see below). Subspecies, if a use of this category would make sense at all, are defined by replacing each other geographically and to show weak gene flow in contact zones.

We had no access to type specimens of Leptothorax luteus var. subcingulata EMERY, 1924. Type localities are Algeciras $\left[36.13^{\circ} \mathrm{N}, 5.47^{\circ} \mathrm{W}\right]$ and Tibidabo $\left[41.42^{\circ} \mathrm{N}\right.$, $2.12^{\circ} \mathrm{E}$ ]. EMERY (1924) noted that only the specimens from Algeciras matched his description fully while those from Tibidabo had a more or less brown antennal club. Plateaux \& Cagniant (2012) had a look on the types from Tibidabo and allocated these to their newly erected subspecies T. luteus racovitzai (BondROIT). However, they did not see the types from Algeciras but assumed that there was a subspecies T. luteus subcingulata (EMERY) in southern Spain. We cannot assess this question and consider Leptothorax luteus var. subcingulata EMERY as a Nomen Dubium as long as there is no access to the types from Algeciras.

\section{Interspecific morphological differences and a simpler method for species delimitation}

The two species are extremely similar, showing a large interspecific overlap for any investigated character even if nest sample means are considered (Tab. 1). A quick species determination by subjective eye inspection seems impossible. T. luteus and T. racovitzai are truly cryptic species according to the definition of SEIFERT (2009). T. racovitzai differs from $T$. luteus by a relatively smaller mesosoma in all three dimensions, a smaller distance of frontal carinae and larger eyes. Pigmentation and sculpture characters are of no use: Both species show very light, almost entirely yellowish forms as well as darker forms with different body parts appearing infuscated while sculpture varies strongly even within nests and as a function of size. Figs 3-6 show two aspects of each species by example of type specimens.

The complex methods of species delimitation presented above appear unacceptable for practitioners of biodiversity research for reasons of time required for learning the methods and for processing of the samples. Hence, it should be asked how much simplification is possible while keeping the error rate at an acceptable level. The first simplification is using absolute measuring data instead of RAV-corrected shape variables and the second one a strong reduction of characters used. Running the 17 primary characters CL, CW, SL, PoOc, FRS, EYE, MW, MH, ML, SPBA, SPTI, SP, SPST, PEW, PPW, PEH and PEL in discriminant analyses with both forward and backward elimination of characters, we selected a discriminant function reduced to four characters:

$$
\begin{aligned}
& =74.496^{\star} \mathrm{FRS}-206.142^{\star} \mathrm{EYE}+57.695^{\star} \mathrm{ML} \\
& -49.634^{\star} \mathrm{CL}+2.636 .
\end{aligned}
$$

This method shows a classification error of $3.9 \%$ on worker individual level and the scores of $\mathrm{D}(4)$ vary in the following way:

T. racovitzai:

$\mathrm{D}(4)=-2.044 \pm 0.88[-4.363,0.041] \mathrm{n}=72$

T. luteus:

$\mathrm{D}(4)=1.388 \pm 1.07[-1.051,4.433] \mathrm{n}=106$

Nest sample means of $\mathrm{D}(4)$ showed no interspecific overlap:

T. racovitzai:

$\mathrm{D}(4)=-1.996 \pm 0.74[-3.113,-0.435] \mathrm{n}=26$

T. luteus:

$\mathrm{D}(4)=1.380 \pm 0.83[-0.157,3.779] \mathrm{n}=38$

This method requires some 10 minutes of investigation time per specimen and should be successful if character definitions are carefully considered and if a sufficient measuring accuracy is achieved.

\section{Distribution and thermal niche}

The presented study intended to investigate the relations in the northern part of both species' geographic ranges, focusing on the situation in the sympatric area. Accordingly, our data are far from depicting the entire geographic ranges. They exclude Spain south of $40^{\circ} \mathrm{N}$ where T. racovitzai should predominate and entire Italy where T. luteus 


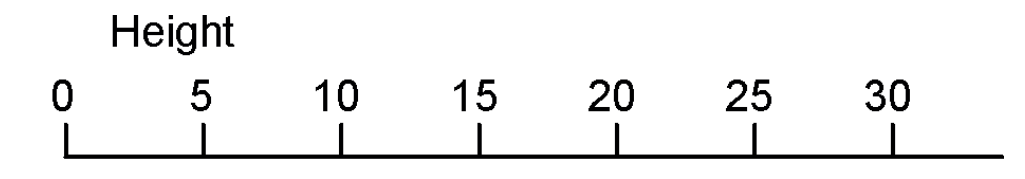

AND_Andorra_City_9NNW_19910518_500a-lute FRA_Rochepaule_200807-lute FRA Le Vigan 15NNW 19940709 39-lute FRA_Volvic_20060629-lute FRA_Cucuron_6NNE_LuberonMts_20090315_577-lute FRA Cucuron 6NNE LuberonMts 20090315 584-lute FRA_Mt_Ventoux_19170812(IRS̄NB_Bruxelles)-lute FRA_Puy_de_Dome_Sayat_20060629-lute AND Andorra City 9NNW 19910518 502-lute FRA_La_Tour_de_Carol_20080628_d-lute FRA Nimes_20080719-lute

FRA La Tour de Carol 20080628 h-lute FRA_Mas_de_Tence_200707(Degache)-lute FRA_St Andre les_Alpes 199505 729-lute FRA_Tournus_5W_19940708_1-lute SW_Locarno_below_Mte_Bre_20110821_1-lute SW Pfynwald 199006 (A Schulz)-lute FRA_Desaigres_200804_(Darras)-lute FRA_St_Andre_les_Alpes_199505_727-lute FRA Puy de Dome Sayat type tristis-lute FRA Tournus 5W $19940 \overline{7} 08$ 4-lute FRA_Cucuron_6NNE_LuberonMTts_20090315_593-lute FRA Grand Saleve chez A Varanen typ lute-lute FRA_Tournus_5W_19940708_5-lute SPA_Chodos_1W_19910518_388-lute FRA Cucuron 6NNE LuberonMts 20090315 574-lute FRA_Cucuron_6NNE_LuberonMts_20090315_590-lute FRA_Cucuron_6NNE_LuberonMts_20090315_594-lute

FRA Puy de Dome Sayat 20060725-lute FRA_S_Col_d_Izoard_Arvieux_19940729_396-lute $\bar{F} \overline{R A}$ Tournus 5W-19940708 007-lute SW Brig No 514 (A Schulz) pre 1991-lute SWILocarno_Ai_Sassi_19970624_25_2-lute SW_Locarno_MonteBre_19970527_24_3-lute SW Locarno_MonteBre-19970429_24_2-lute FRA_Aix_en_Provence_10N_20090313_535-raco SPA Montsant Mts $2007040 \overline{3}$ 16-raco FRA Cerbere 200709-raco SPA_Pauls_vic_20091021_627-raco

FRA Marseille(Grouvelle) typ massi-raco FRA_Apt_10S_Luberon_Mts_20090314_565-raco FRA_Banyuls_20090613-raco FRA Cerbere 20050615-raco FRA_Col_de_Ceris_20070623-raco FRA_Cucuron_6NNE_LuberonMts_20090315_596-raco SPA Colldejou 20091020 600-raco FRA_Banyuls_type_racovitzai-raco SPA_Viella_Baixa_20091023_640-raco FRA Mt Ventoux 201000822-raco SPA_Chodos_1W_19910518_380-raco SPA_Torroja_del_Priorat 20070403 15-raco FRA Cucuron 6 NNE LuberonMts_20090315 597-raco SPA_Pauls_vic_20091021_628-raco FRA_Banyuls_4SE_19950531_799-raco FRA Dieulefit(Forel)-raco FRA_Col_de_Banyuls_200908-raco SPA Colldejou 20091020 599-raco SPA_Colldejou_20091020_601-raco SPA_Montsant_Mts_20070403_18-raco FRA_Gr_Canyon_du_Verdon_199205-lute

$\longrightarrow$ FRA_Nyons_19810402_9714-lute FRA_Nyons_19810402_9712-raco FRA Aix en Provence 199406-raco $\longrightarrow$ FRA_Laruns_20090716_(PGI)-lute

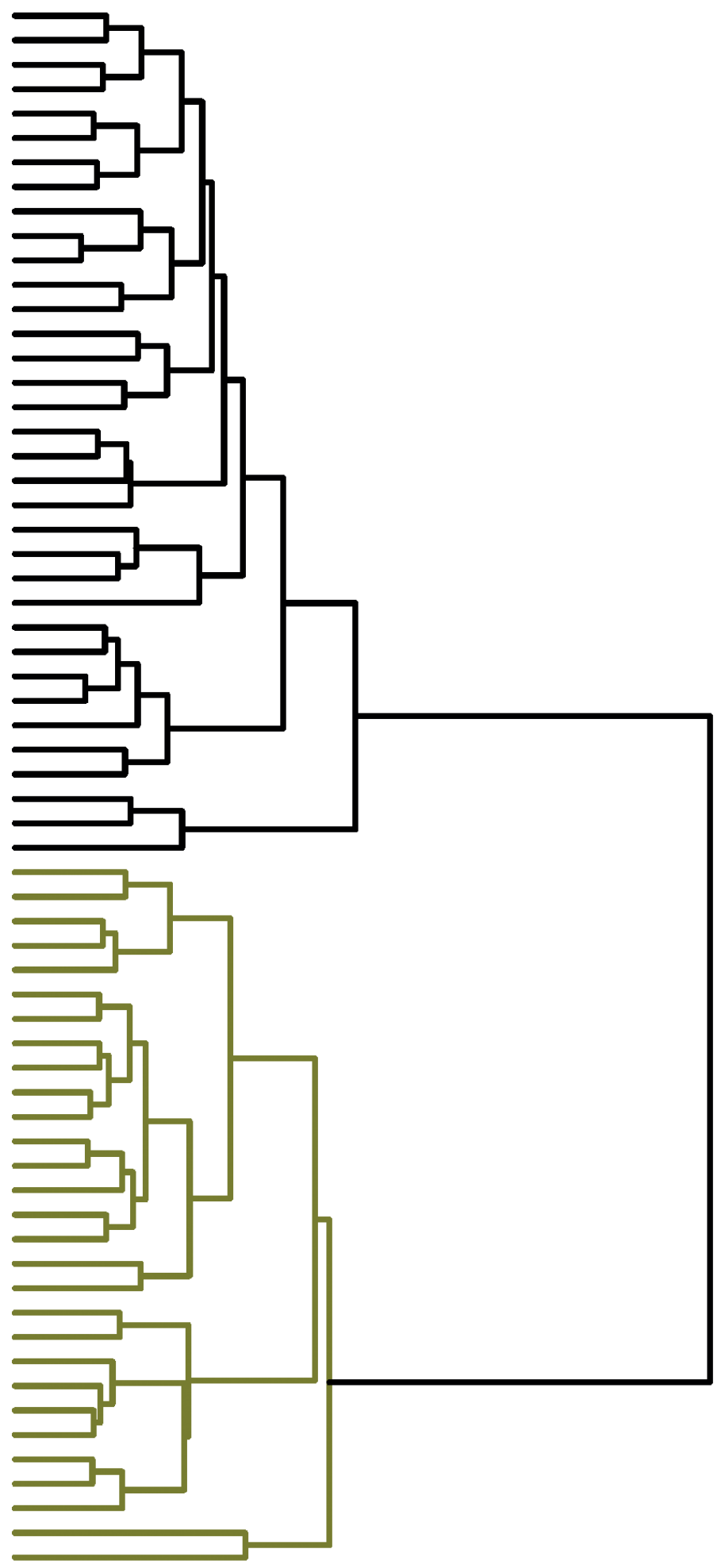

Fig. 1: NC-Ward clustering of 64 worker nest samples of Temnothorax luteus (ForeL, 1874) and T. racovitzai (BondRoIT, 1918) considering 18 unselected morphometric characters. Arrows point to three nest samples of T. luteus erroneously placed in the T. racovitzai cluster. 
Tab. 1: Morphometric data of nest sample means of workers of Temnothorax luteus and T. racovitzai. Removal of allometric variance of shape variables was performed for the assumption of each individual having a head size of CS $=0.62 \mathrm{~mm}$. Arrangement of data: arithmetic mean \pm standard deviation [minimum, maximum] and in falling order of significance in an univariate ANOVA.

\begin{tabular}{|c|c|c|c|c|}
\hline & T. racovitzai $(\mathrm{n}=26)$ & ANOV & $F, p$ & T. luteus $(\mathrm{n}=38)$ \\
\hline $\mathrm{ML} / \mathrm{CS}_{0.62}$ & $1.171 \pm 0.014 \quad[1.151,1.197]$ & 109.93 & 0.000 & $1.214 \pm 0.017 \quad[1.156,1.244]$ \\
\hline $\mathrm{EYE} / \mathrm{CS}_{0.62}$ & $0.226 \pm 0.005 \quad[0.215,0.238]$ & 74.40 & 0.000 & $0.216 \pm 0.004 \quad[0.206,0.226]$ \\
\hline $\mathrm{FRS} / \mathrm{CS}_{0.62}$ & $0.319 \pm 0.007 \quad[0.306,0.330]$ & 67.44 & 0.000 & $0.337 \pm 0.009 \quad[0.322,0.355]$ \\
\hline $\mathrm{MH} / \mathrm{CS}_{0.62}$ & $0.491 \pm 0.011 \quad[0.460,0.511]$ & 62.58 & 0.000 & $0.517 \pm 0.014 \quad[0.482,0.545]$ \\
\hline $\mathrm{MW} / \mathrm{CS}_{0.62}$ & $0.597 \pm 0.011 \quad[0.573,0.623]$ & 52.28 & 0.000 & $0.616 \pm 0.010 \quad[0.592,0.637]$ \\
\hline $\mathrm{SPBA} / \mathrm{CS}_{0.62}$ & $0.259 \pm 0.011 \quad[0.242,0.296]$ & 24.29 & 0.000 & $0.272 \pm 0.009 \quad[0.252,0.290]$ \\
\hline $\mathrm{PEW} / \mathrm{CS}_{0.62}$ & $0.249 \pm 0.005 \quad[0.241,0.260]$ & 23.58 & 0.000 & $0.257 \pm 0.006 \quad[0.245,0.277]$ \\
\hline $\mathrm{PEH} / \mathrm{CS}_{0.62}$ & $0.345 \pm 0.010 \quad[0.330,0.369]$ & 18.06 & 0.000 & $0.356 \pm 0.010 \quad[0.339,0.378]$ \\
\hline $\mathrm{CS}[\mu \mathrm{m}]$ & {$[522,638]$} & 15.07 & 0.000 & {$[504,692]$} \\
\hline $\mathrm{SPST} / \mathrm{CS}_{0.62}$ & $0.314 \pm 0.012 \quad[0.298,0.338]$ & 6.74 & 0.012 & $0.324 \pm 0.016 \quad[0.282,0.355]$ \\
\hline $\mathrm{SPTI} / \mathrm{CS}_{0.62}$ & $0.341 \pm 0.018 \quad[0.308,0.379]$ & 6.32 & 0.015 & $0.352 \pm 0.017 \quad[0.327,0.388]$ \\
\hline $\mathrm{PPW} / \mathrm{CS}_{0.62}$ & $0.339 \pm 0.009 \quad[0.316,0.355]$ & 6.19 & 0.016 & $0.346 \pm 0.011 \quad[0.317,0.368]$ \\
\hline $\mathrm{PoOc} / \mathrm{CL}_{0.62}$ & $0.383 \pm 0.005 \quad[0.372,0.390]$ & 4.97 & 0.029 & $0.386 \pm 0.006 \quad[0.370,0.400]$ \\
\hline $\mathrm{CL} / \mathrm{CW}_{0.62}$ & $1.130 \pm 0.012 \quad[1.108,1.156]$ & 2.18 & n.s. & $1.135 \pm 0.015 \quad[1.103,1.172]$ \\
\hline $\mathrm{PEL} / \mathrm{CS}_{0.62}$ & $0.521 \pm 0.012 \quad[0.498,0.545]$ & 0.57 & n.s. & $0.518 \pm 0.013 \quad[0.498,0.556]$ \\
\hline $\mathrm{SL} / \mathrm{CS}_{0.62}$ & $0.815 \pm 0.015 \quad[0.792,0.842]$ & 0.38 & n.s. & $0.818 \pm 0.021 \quad[0.758,0.852]$ \\
\hline $\mathrm{MPGR} / \mathrm{CS}_{0.62}[\%]$ & {$[0.00,0.27]$} & 0.34 & n.s. & {$[0.00,0.67]$} \\
\hline $\mathrm{SP} / \mathrm{CS}_{0.62}$ & $0.234 \pm 0.018 \quad[0.198,0.274]$ & 0.00 & n.s. & $0.235 \pm 0.016 \quad[0.186,0.266]$ \\
\hline
\end{tabular}

Tab. 2: Distributional data of Temnothorax luteus and T. racovitzai collapsed to sites sampled. Arrangement of data: arithmetic mean \pm standard deviation [minimum, maximum]. Significance testing by an univariate ANOVA.

\begin{tabular}{|c|c|c|c|c|c|}
\hline & $\begin{array}{c}\text { number } \\
\text { of sites }\end{array}$ & $\operatorname{LAT}\left[{ }^{\circ}\right]$ & $\operatorname{LON}\left[^{\circ}\right]$ & ALT $[\mathrm{m}]$ & TAS $\left[{ }^{\circ} \mathrm{C}\right]$ \\
\hline T. racovitzai & 21 & $42.58 \pm 1.23[40.25,44.50]$ & $3.24 \pm 2.00[-0.30,5.59]$ & $479 \pm 392[10,1250]$ & $18.99 \pm 2.30[14.84,22.72]$ \\
\hline ANOVA & & $\mathrm{p}<0.0001$ & $\mathrm{~F}=5.72 \quad \mathrm{p}<0.021$ & $\mathrm{~F}=9.30 \quad \mathrm{p}<0.004$ & $\mathrm{p}<0.0001$ \\
\hline T. luteus & 24 & $44.65 \pm 1.56[40.25,46.58]$ & $4.92 \pm 2.62[-0.45,8.80]$ & $848 \pm 417[50,1750]$ & $15.22 \pm 2.56[9.43,21.26]$ \\
\hline
\end{tabular}

should abound. Yet, even this reduced data set revealed significant interspecific differences in geographic distribution and thermal niche (Tab. 2). T. racovitzai is the more southern and western species which occurs in the sympatric range at lower elevations. Its postglacial expansion most certainly started from an Iberian refuge while the Pleistocene refuge of T. luteus most probably was somewhere in the central or southern Apennine. The most striking interspecific difference exists in the thermal component of climatic niche: air temperature from May to August is by $3.77^{\circ} \mathrm{C}$ cooler in the sampling sites of T. luteus than in those of $T$. racovitzai.

Two experienced ant collectors, who were not able to distinguish the cryptic species and having studied the situation in S France, independently expressed the opinion that workers of the T. luteus complex grow to a larger size (and develop a darker color) in cooler environments. These impressions are true but they were generated by the fact that the significantly larger species T. luteus (Tab. 1) occurs in significantly cooler environments (Tab. 2). Linear regression analyses within the species showed no significant negative dependence of the body-size indicator CS from environmental temperature TAS:

T. luteus:

CS $=-0.0004$ TAS $+0.629(\mathrm{r}=-0.0219$, n.s., $\mathrm{n}=38)$. T. racovitzai:

CS $=-0.0024$ TAS $+0.631(r=-0.1897$, n.s., $n=26)$.

\section{Acknowledgements}

We wish to thank Anne Freitag (MZ Lausanne) and Wouter Dekoninck (IRSNB Bruxelles) for allowing a loan of type specimens from the Forel and Bondroit collections. 


\section{References}

Casevitz-Weulersse, J. \& Galkowski, C. 2009: Liste actualisée des Fourmis de France (Hymenoptera, Formicidae). - Bulletin de la Société entomologique de France 114 (4): 475-510.

Csösz, S; Seifert, B; Müller, B.; Trindl, A.; Schulz, A. \& Heinze, J. 2013: Cryptic diversity in the Mediterranean Temnothorax lichtensteini species complex (Hymenoptera: Formicidae). - Organisms, Diversity \& Evolution 14: 75-88. DOI: 10.1007/ s13127-013-0153-3.

Emery, C. 1924: Formiche di Spagna, raccolte dal Prof. Filippo Silvestri. - Bolletino del Laboratorio di Zoologia generale e agraria della R. Scuola superiore d' Agricoltura in Portici 17: 164-171.

Klimaabteilung der Zentralanstalt für Meteorologie und Geodynamik 1996: Klimadaten der Welt aufCD-ROM. Version 1.0. Zentralanstalt für Meteorologie und Geodynamik, Vienna. 1 CD-ROM.

Plateaux, L. \& Cagniant, H. 2012: Quelques synonymies dans le genre Temnothorax MAYR, 1855 (Hymenoptera, Formicidae). - Bulletin de la Société entomologique de France 117 (4): 427-440.

Seifert, B. 2002: How to distinguish most similar insect species - improving the stereomicroscopic and mathematical evaluation of external characters by example of ants. - The Journal of Applied Entomology 126: $445-454$.
SEIfERT, B. 2006: Temnothorax saxonicus (SEIFERT, 1995) stat. nov., comb. nov. - a parapatric, closely-related species of T. sordidulus (MüLLER, 1923) comb. nov., stat. nov. and description of two new closelyrelated species, T. schoedli sp.n. and T. artvinense sp. n. from Turkey (Hymenoptera: Formicidae). Myrmecological News 8: 1-12.

SEIFERT, B. 2008: Removal of allometric variance improves species separation in multi-character discriminant functions when species are strongly allometric and exposes diagnostic characters. - Myrmecological News 11: 91-105.

SeIfert, B. 2009: Cryptic species in ants (Hymenoptera: Formicidae) revisited: we need a change in the alphataxonomic approach. - Myrmecological News 12: 149-166.

Seifert, B. \& PAnier, L. 2007: A method for standardized description of soil temperatures in terrestrial ecosystems. - Abhandlungen und Berichte des Naturkundemuseums Görlitz 78: 151-182.

Seifert, B.; Ritz, M. \& Csösz, S. 2013: Application of Exploratory Data Analyses opens a new perspective in morphology-based alpha-taxonomy of eusocial organisms. - Myrmecological News 19: 1-15. 


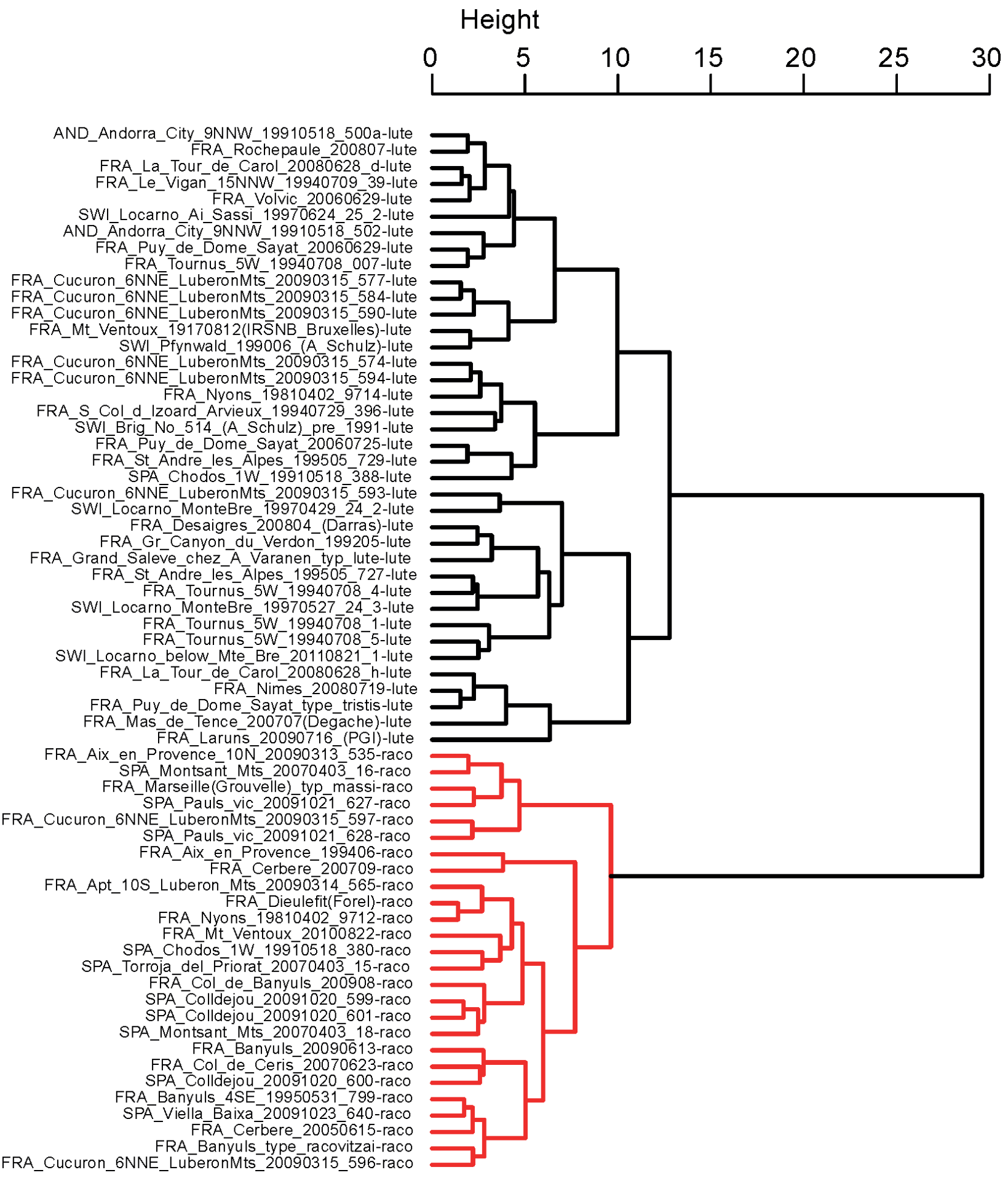

Fig. 2: NC-Ward clustering of 64 worker nest samples of Temnothorax luteus (Forel, 1874) and T. racovitzai (BondroIT, 1918) considering 7 selected morphometric characters. 

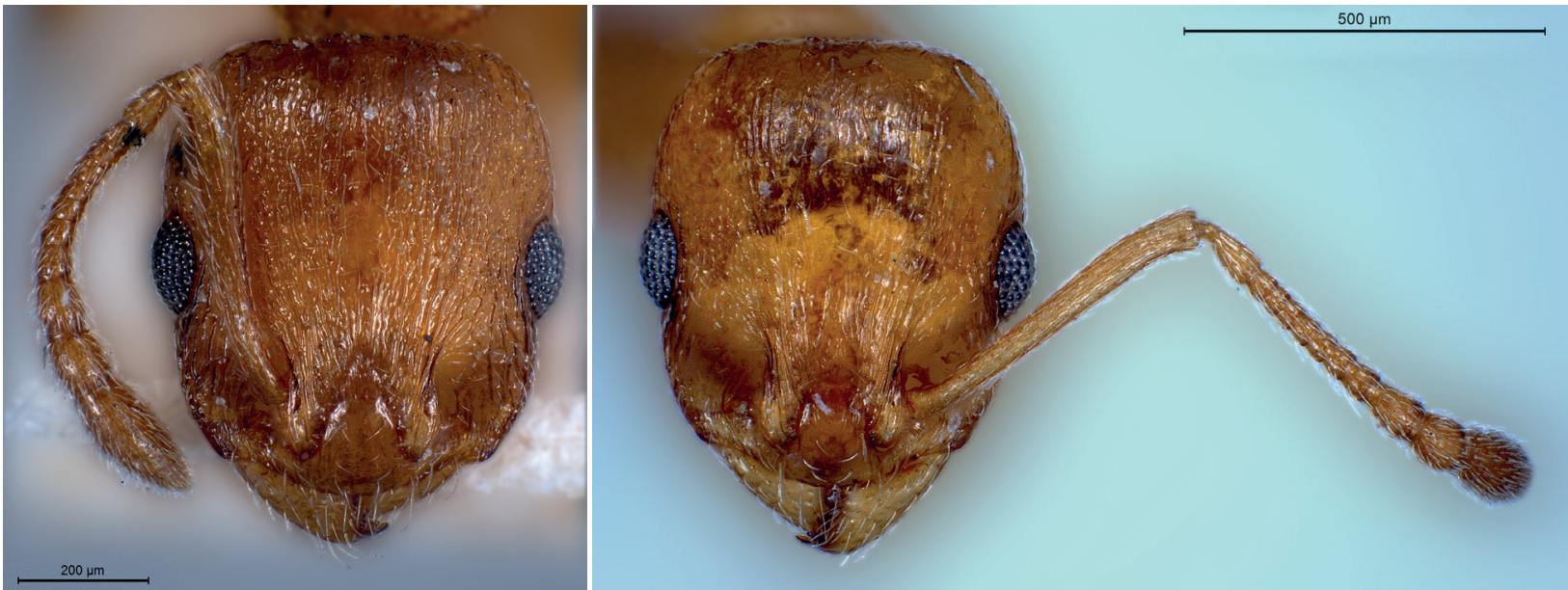

Fig. 3: Head of Temnothorax luteus (Forel, Fig. 5: Head of lectotype of Temnothorax racovitzai (Bondroit, 1918). 1874); shown is the type of the junior synonym Temnothorax tristis (BONDROIT, 1918).

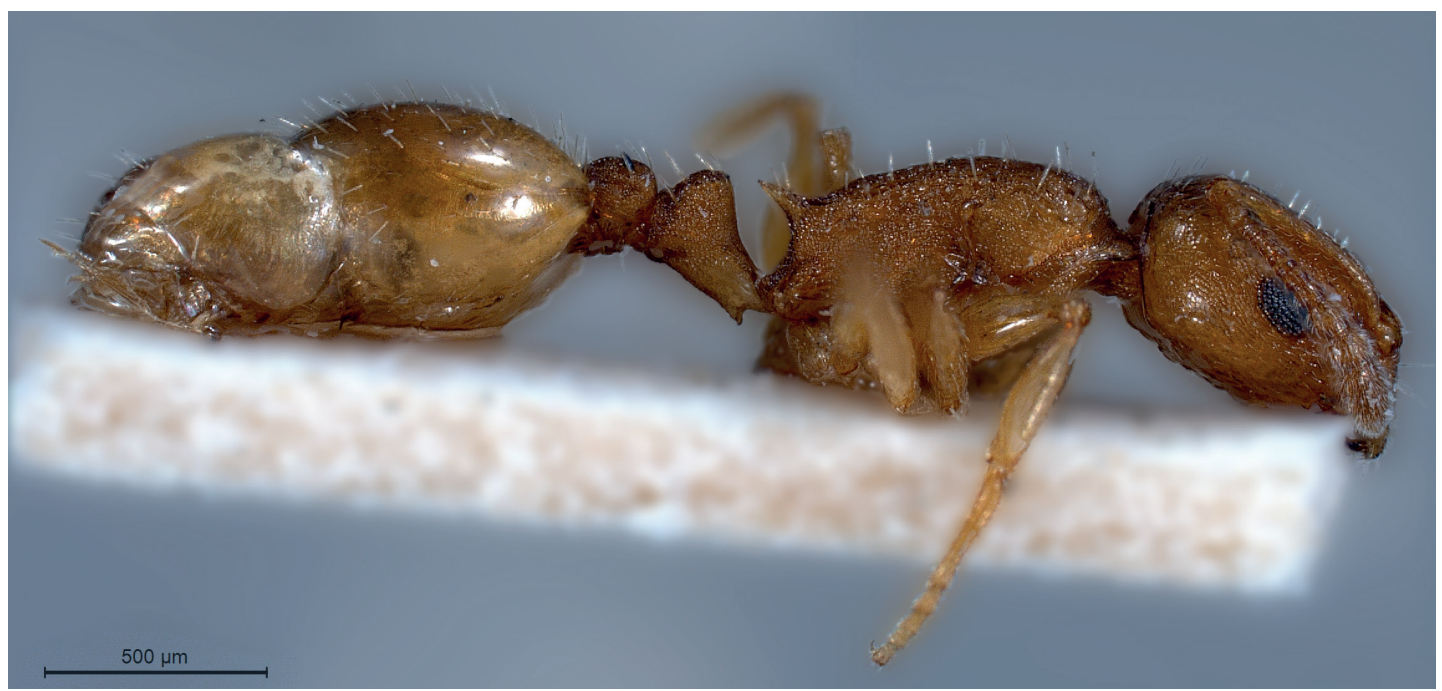

Fig. 4: Temnothorax luteus (FOREL, 1874) in lateral view; shown is the type of the junior synonym Temnothorax tristis (BONDROIT, 1918).

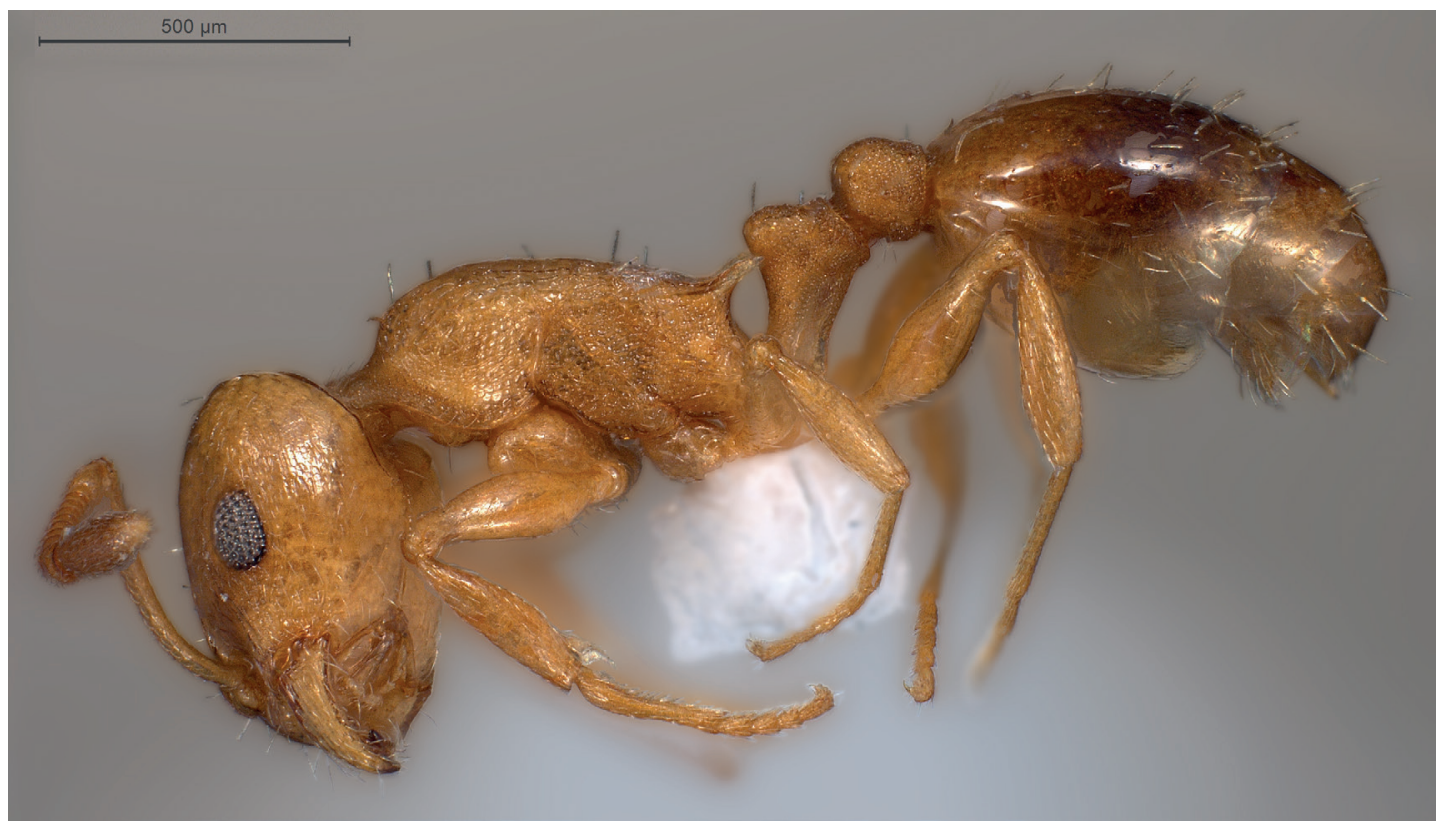

Fig. 6: Lectotype of Temnothorax racovitzai (BondRoIT, 1918) in lateral view. 